\title{
JPSE
}

(Journal of Physical Science and Engineering)

\section{A Study of Palladium-Nickel Catalyst for Direct Synthesis of Hydrogen Peroxide: A DFT Approach}

\begin{tabular}{l}
\hline Received \\
10 August 2020 \\
Revised \\
18 October 2020 \\
Accepted for Publication \\
20 October 2020 \\
Published \\
23 October 2020 \\
\hline
\end{tabular}

\author{
M Nugraha ${ }^{1 *}$, N Setyasmara ${ }^{2}$, and S Pupon ${ }^{1}$ \\ 1. Department of Printing Technology, Politeknik Negeri Media Kreatif, Jl. Srengseng Sawah \\ Jagakarsa, South Jakarta, 12640, Indonesia. \\ 2. Department of Graphic Desain, Politeknik Negeri Media Kreatif, Jl. Srengseng Sawah Jagakarsa, \\ South Jakarta, 12640, Indonesia. \\ *E-mail: mawan@polimedia.ac.id
}

\begin{abstract}
Hydrogen peroxide is an important material for bleaching agent in paper production related to the low price and environmentally friendly chemical. The current production of $\mathrm{H}_{2} \mathrm{O}_{2}$ is well-known as indirect synthesis, which uses danger anthraquinone. The synthesis was improved by using the direct reaction of $\mathrm{H}_{2}$ and $\mathrm{O}_{2}$ on Pd or PdAu alloy's catalyst surface and has been known as direct synthesis. The current catalyst used is Pd-Au, but it has limited availability in nature. Therefore we need the alternative of Pd-Au. We investigated $\mathrm{Ni}$ alloyed with $\mathrm{Pd}$ for the new $\mathrm{H}_{2} \mathrm{O}_{2}$ direct synthesis using density functional theory approach. The 7 -slab model with $2 \times 2$ surface size was used for the calculation using $\mathrm{ab}$ initio simulation package. We selected the $\mathrm{O}$ adsorption to screen the catalysts and compared the species adsorption trend on the surfaces of PdNi and the proven catalysts such as Pd, PdAu, and PdHg. Since the trend of O adsorption on the PdAu and PdNi is similar, it can be concluded that the catalytic selectivity of PdNi equal with PdAu. Further, the stability of PdNi alloy was explored by calculating the binding and compared it with $\mathrm{Pd}$, which leads to the conclusion that $\mathrm{PdNi}$ can be a good catalyst for $\mathrm{H}_{2} \mathrm{O}_{2}$ synthesis.

Keywords: Palladium-nickel, catalyst, $\mathrm{H}_{2} \mathrm{O}_{2}$ synthesis, density functional theory.
\end{abstract}

\section{Introduction}

Hydrogen peroxide $\left(\mathrm{H}_{2} \mathrm{O}_{2}\right)$ is an important chemical used in many industries, such as detergent, medical/pharmaceutical, paper, and fine chemical manufactures. In the paper industry, $\mathrm{H}_{2} \mathrm{O}_{2}$ was used as a bleaching agent, which diluted the lignin to screen the cellulose and improve the color by removing the unwanted colored material from the pulp [1]. The production of $\mathrm{H}_{2} \mathrm{O}_{2}$ reached 2.2 million metric tons, of the $60 \%$ was used for paper production. The rest was used to clean agents and solvent cosmetics, medicine, and others [2]. The use of $\mathrm{H}_{2} \mathrm{O}_{2}$ in papermaking was driven by a green issue related to chlorine and halogen compound, which poisoned the environment [3]. The $\mathrm{H}_{2} \mathrm{O}_{2}$ was a green chemical compared with halogen-based compound since the side product of the $\mathrm{H}_{2} \mathrm{O}_{2}$ reaction was water [4].

The need for $\mathrm{H}_{2} \mathrm{O}_{2}$ always increases annually caused by the growth of fine chemical needs in the industry. For example, propylene epoxidation's commercialization was getting more important due to the hydrogen peroxide propylene oxide (HPPO) needed to synthesize other chemicals [5]. The growth trend was unstoppable in accordancewith the need of a cleaning agent in electronic industry. Based on the importance of $\mathrm{H}_{2} \mathrm{O}_{2}$ in human life, producing it has become attractive for the researchers to explore.

The production method of $\mathrm{H}_{2} \mathrm{O}_{2}$ has been known as an indirect synthesis of hydrogen peroxide (ISHP), which used anthraquinone as auto-oxidation agent. However, the anthraquinone was dangerous for humans and the environment [6]. To have more green production of $\mathrm{H}_{2} \mathrm{O}_{2}$, avoiding the use of anthraquinone was needed. The term of direct synthesis of hydrogen peroxide (DSHP) was proposed to substitute the ISHP [7]. The DSHP meant the forming of $\mathrm{H}_{2} \mathrm{O}_{2}$ occurred directly from $\mathrm{H}_{2}$ and $\mathrm{O}_{2}$ on the catalyst surface. Even though the DSHP seemed a simpler step than ISHP, there were some possible reactions on the catalyst as follow [8],

$$
\mathrm{H}_{2}+\mathrm{O}_{2} \rightarrow \mathrm{H}_{2} \mathrm{O}_{2}(l), \Delta \mathrm{G}_{0} 298 \mathrm{~K}=-120.4 \mathrm{~kJ} / \mathrm{mol}
$$


The symbol of $\Delta \mathrm{G}_{0} 298 \mathrm{~K}$ means the free energy of a substance reaction measured under the conditions of $1 \mathrm{~atm}$ pressure or an effective concentration of 1 molar and a temperature of $298 \mathrm{~K}$. In fact, the $\mathrm{H}_{2} \mathrm{O}_{2}$ could be easy to dissociate becoming water since the energy was closed to the $\mathrm{H}_{2} \mathrm{O}_{2}$ forming as follow

$$
\mathrm{H}_{2} \mathrm{O}_{2}(l) \rightarrow \mathrm{H}_{2} \mathrm{O}(l)+1 / 2 \mathrm{O}_{2}, \Delta \mathrm{G}_{0} 298 \mathrm{~K}=-116.8 \mathrm{~kJ} / \mathrm{mol}
$$

The $\mathrm{H} 2$ gas in the presence of water also leads to form further water as follow

$$
\mathrm{H}_{2} \mathrm{O}(l)+\mathrm{H}_{2} \rightarrow 2 \mathrm{H}_{2} \mathrm{O}(l), \Delta \mathrm{G}_{0} 298 \mathrm{~K}=-354.0 \mathrm{~kJ} / \mathrm{mol}
$$

Besides, there was non-selective reaction which thermodynamically preferred as follow

$$
\mathrm{H}_{2}+1 / 2 \mathrm{O}_{2} \rightarrow \mathrm{H}_{2} \mathrm{O}(l), \Delta \mathrm{G}_{0} 298 \mathrm{~K}=-237.2 \mathrm{~kJ} / \mathrm{mol}
$$

The Gibbs free energy showed in (1) to (2) was calculated by the previous research [8]. From the reactions fore mentioned, (1) and (2) competed with each other, and (4) was preferable. Since the direct forming of $\mathrm{H}_{2} \mathrm{O}$ on the catalyst was more likely than $\mathrm{H}_{2} \mathrm{O}_{2}$, the researchers investigated the suitable catalyst that optimized the selective forming toward $\mathrm{H}_{2} \mathrm{O}_{2}$ product.

The well-known catalyst for this area was the alloy of palladium-gold ( $\mathrm{PdAu})$, which reached the selectivity to 95\% [8]. This alloy has replaced the use of monometallic Pd which had lower selectivity toward $\mathrm{H}_{2} \mathrm{O}_{2}$ compared with the use of $\mathrm{PdAu}$ alloy catalyst.

The reaction of $\mathrm{H}_{2} \mathrm{O}_{2}$ forming on the catalyst surface followed the steps such as (a) the adsorption of molecular oxygen $\left(\mathrm{O}_{2}\right)$ and hydrogen $\left(\mathrm{H}_{2}\right)$ occurred on the catalyst surface, (b) the adsorbed $\mathrm{O}_{2}$ was maintained on the catalyst surface and noted as surface molecular oxygen $\left(\mathrm{O}_{2}{ }^{*}\right)$ while $\mathrm{H}_{2}$ was dissociated becoming $2 \mathrm{H}^{*}$ (the $*$ symbolized a surface species), (c) $\mathrm{O}_{2} *$ was hydrogenated becoming $\mathrm{OOH}^{*}$, and further hydrogenation as $\mathrm{HOOH}^{*}$; (d) $\mathrm{HOOH}^{*}$ was released from the catalyst surface to form $\mathrm{H}_{2} \mathrm{O}_{2}(l)$ [9], [10].

The presence of $\mathrm{Au}$ in the surface of $\mathrm{PdAu}$ alloy catalyst weakened the bonding of $\mathrm{Pd}-\mathrm{O}_{2}$ compared with the binding on the monometallic Pd catalyst. The stronger the $\mathrm{O}_{2}$ surface bonding, the easier for $\mathrm{O}_{2}$ to dissociate, becoming $2 \mathrm{O}^{*}$, which leads to the more difficult to form $\mathrm{OOH}^{*}$. The weaker the $\mathrm{O}_{2}$ surface bonding, the easier $\mathrm{O}_{2}$ released from the surface, and $\mathrm{OOH}^{*}$ could not be formed [4]. Therefore, in the $\mathrm{H}_{2} \mathrm{O}_{2}$ forming, the bonding of the $\mathrm{O}_{2}$ surface did not need too strong or weak.

The drawback of PdAu alloy catalyst was the use of expensive metal, as seen in Table 1 [16]. $\mathrm{PdAu}$ also needed acid condition to optimize the selectivity, which needs to be improved, such as avoiding the use of acid to have cleaner production. Therefore, finding the alternative catalyst might help to get friendly environment production compared with a current catalyst such as PdAu alloy. Using the more abundant material of catalyst, which had the same selectivity as the current, could also improve the production cost, which meant it supported the green synthesis of $\mathrm{H}_{2} \mathrm{O}_{2}$. Some researchers have proposed alternative catalysts to replace the use of PdAu alloy catalysts. For example, palladiumplatinum alloy (PdPt) was the more stable catalyst compared with PdAu, however, PdPt did not offer better catalytic performance compared with PdAu. PdPt did not also indicate low-cost material, which lead not to be a favorite choice for replacing PdAu alloy catalyst [11]. Palladium-mercuri alloy (PdHg) showed a better alternative catalyst compared to PdAu related to the selectivity toward $\mathrm{H}_{2} \mathrm{O}_{2}$ forming by ab initio study [4]. Since $\mathrm{Hg}$ might offer serious poisoning for humans and the environment, the choice of PdHg could not be a good alternative for replacing PdAu alloy catalyst. Paladium-silver alloy $(\mathrm{PdAg})$ has also been proposed to replace the use of PdAu, but the study showed PdAg alloy had no better catalytic performance than PdAu alloy [12], [13].

Palladium nickel alloy (PdNi) indicated a catalytic capacity for $\mathrm{H}_{2} \mathrm{O}_{2}$ direct synthesis based on previous work [14]. However, the mechanism of Ni role in the PdNi was still unclear. The availability of $\mathrm{Ni}$ in nature was more abundant than $\mathrm{Au}$, which offered more benefits based on the price. For example, Indonesia had a stock of Ni reached 137 thousand wet metric tons (wmt) [15]. In this study, we want to confirm the catalytic capacity of PdNi for DSHP compared with Pd monometallic and PdAu alloy catalysts. 
Table 1. The world price metal per OZT (Troy ONZ).

\begin{tabular}{lc}
\hline \multicolumn{1}{c}{ Metal } & $\begin{array}{c}\text { Price } \\
\text { (USD/ OZT) }\end{array}$ \\
\hline Palladium (Pd) & 1,567 \\
\hline Gold $(\mathrm{Au})$ & 1,515 \\
\hline Platinum $(\mathrm{Pt})$ & 841 \\
\hline Silver $(\mathrm{Ag})$ & 15.4 \\
\hline Nickel $(\mathrm{Ni})$ & 6.0 \\
\hline
\end{tabular}

Considering the drawback of PdAu alloy catalyst, this work offered the finding technique of the alternative catalyst which is abundant in Indonesia and globally environmentally friendly. The presence of $\mathrm{O}_{2}{ }^{*}$ and $\mathrm{H}^{*}$ on the catalyst surface is the key, which leads to the two-step mechanism of $\mathrm{O}_{2}{ }^{*}$ hydrogenation to form $\mathrm{H}_{2} \mathrm{O}_{2}$ [7]. The overall reactions of $\mathrm{H}_{2} \mathrm{O}_{2}$ forming directly on the surface are written in the reaction (5) to (14) In the direct synthesis of hydrogen peroxide, starting from stable adsorbed $\mathrm{O}_{2}$ and dissociative adsorption of $\mathrm{H}_{2}$.

The $\mathrm{O}_{2} *$ was hydrogenated to form $\mathrm{OOH}^{*}$ (reaction (5)) as the first step hydrogenation. The intermediate $\mathrm{OOH}^{*}$ was further hydrogenated to $\mathrm{HOOH}^{*}$, which was released from the surface results $\mathrm{H}_{2} \mathrm{O}_{2}$ (reaction (8)). However, at the same time of $\mathrm{OOH}$ hydrogenation reaction (reaction (8)), $\mathrm{H}_{2} \mathrm{O}$ can also be formed as reaction (9), as well as $\mathrm{OH}$ species forming for reaction (10) and (11). However, if the interaction of $\mathrm{OOH}^{*}$ and surface is weak, the $\mathrm{OOH}^{*}$ may be released as a reaction (12) [9].

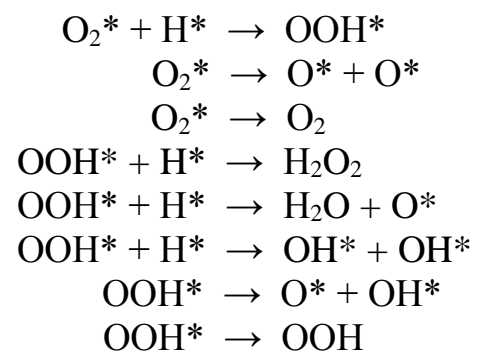

The target $\mathrm{H}_{2} \mathrm{O}_{2}$ can be dissociated to $2 \mathrm{OH}^{*}$ (reaction (13)) or attached on the surface as reaction (14).

$$
\begin{aligned}
& \mathrm{H}_{2} \mathrm{O}_{2} * \rightarrow \mathrm{OH}^{*}+\mathrm{OH}^{*} \\
& \mathrm{H}_{2} \mathrm{O}_{2} * \rightarrow \mathrm{H}_{2} \mathrm{O}_{2}
\end{aligned}
$$

If the presence of $\mathrm{H}^{*}$ is excessive on the surface, further hydrogenation of $\mathrm{H}_{2} \mathrm{O}_{2} *$ may occur to form $\mathrm{H}_{2} \mathrm{O}$ as a reaction (15) [17].

$$
\mathrm{H}_{2} \mathrm{O}_{2} *+\mathrm{H}^{*} \rightarrow 2 \mathrm{H}_{2} \mathrm{O}+\mathrm{OH}^{*}
$$

Research on finding the new catalyst is always attractive since environmental challenges such as global warming and limited energy resource become a big issue for human life. By the role of $\mathrm{H}_{2} \mathrm{O}_{2}$, which used in a wide range of human life such as the production of detergent, medicine, paper, and textile, the catalyst used for direct synthesis of $\mathrm{H}_{2} \mathrm{O}_{2}$ is often reported. The catalyst needs to have good performance in durability, reactivity, selectivity, and environmentally friendly to fulfill the human need of $\mathrm{H}_{2} \mathrm{O}_{2}$. The alternative catalyst was studied in single metal [18] or bimetallic as the surface alloy or core-shell system. The alloy catalyst was reported as $\mathrm{PdHg}$ [4], $\mathrm{AuCu}$ [19], $\mathrm{PdAu}$ [20], and PdAg [21].

Another strategy to get selective catalyst is alloying the metal to modify the surface electronic or local geometric structure [22], which improve reaction rate, change product selectivity and avoid catalyst deactivation [23]. The well-known Pd-based catalyst for $\mathrm{H}_{2} \mathrm{O}_{2}$ direct synthesis is $\mathrm{PdAu}$ alloy, which showed $80 \%$ selectivity without halide promotor and acid condition [3], [13], [24]. By halide promotor, acid condition, and support $\mathrm{TiO}_{2}$, the selectivity of PdAu alloy can be improved to 95\% [25], although the ratio of $\mathrm{Pd}$ or $\mathrm{Au}$ and experimental condition need to be strongly considered [26]. 
The role Au alloyed to Pd is suppressing molecular oxygen dissociation to atomic oxygen on Pd site [27]. From this view, minimizing the atomic oxygen formation on the surface may avoid water formation and support $\mathrm{H}_{2} \mathrm{O}_{2}$ formation as the main target [25]. Therefore, the new catalyst should maintain the adsorbed $\mathrm{O}_{2}$ first on the surface and then facilitate the $\mathrm{OOH}$ formation through hydrogenation reaction. The next step that took place on the catalyst surface is further hydrogenation of $\mathrm{OOH}$ to get $\mathrm{HOOH}$. Therefore, determining the adsorption of $\mathrm{O}_{2}$ on the catalyst surface may be a catalyst screening for several suspected candidate catalysts towards the better catalyst finding.

In this work, we explore PdNi alloy, whether it is possible to be a catalyst and Pd or PdAu alloy based on the theoretical approach. PdNi alloy as a catalyst of $\mathrm{H}_{2} \mathrm{O}_{2}$ direct synthesis has rarely been explored before. The exploration of PdNi as a catalyst candidate was done by observing its adsorption energy and comparing it to the well-known catalyst such as PdAu alloy. The comparison of adsorption energy between Pd and PdAu has been done [4], [9], which indicated the role of Au in the PdAu alloy surface is to decrease the adsorption energy of $\mathrm{O}_{2}$ on the surface compared to the monometallic $\mathrm{Pd}$ catalyst surface. By comparing the adsorption energy of $\mathrm{O}_{2}$ on PdNi to that on Pd, the potency of PdNi as a new catalyst of $\mathrm{H}_{2} \mathrm{O}_{2}$ direct synthesis can be defined.

\section{Method}

2.1. Design

In this work, the adsorption energy data were calculated using ab initio computational program that common for density functional theory (DFT) approach. Some requirements of the calculation were defined as follow, (a) the electron wave function was assumed as a plane wave with $400 \mathrm{eV}$ of the kinetic energy cut off; (b) the interaction of electron valence and nucleus was defined using plane augmented wave (PAW) approach with Purdue and Engelholf (PE) basis set and general gradient approximation (GGA); (c) the Brillouin Zone was sampled in Monkhorst-Pack, with $k$ mesh point $3 \times$ $3 \times 1$ grid sampling; and (d) Gaussian smearing (width $0,1 \mathrm{eV}$ ) was used for electronic occupancy. Convergence criteria for self-consistency were set up at $1 \times 10^{-5} \mathrm{eV}$ with $0.05 \mathrm{eV} / \AA$ of force energy. During optimization, the volume and shape of the model were not allowed.

\subsection{Procedure and Data Collection}

The slab model was used to conduct the calculation. The optimum slab number was observed by comparing the model's atomic energy for 4 to 12 slabs. The slab model then was determined by the principal, i.e., the lower the energy per atom, the more stable the model. However, to choose the slab number, stability of the model and time consumption of the calculation were also considered. The model of $2 \times 2 \operatorname{Pd}(111)$ with 4 to 12 of the slab number was built, as seen in Figure 1. Based on Figure 1, the energy of Pd atom was calculated using equation 16

$$
E / n=\frac{1}{n} E_{t o t}
$$

where $\mathrm{n}$ is the number of an atom and is energy per atom, in one slab of a model, there are four atoms. Therefore we can calculate energy per atom in specific slab model as seen in Table 2.

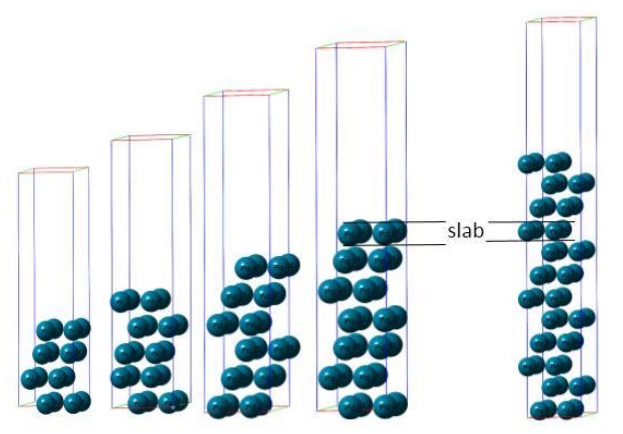

Figure 1. The $2 \times 2$ slab model structure of $\operatorname{Pd}(111)$ with 4 to 12 of the slab number. 
Table 2. Total energy and energy per atom of the model.

\begin{tabular}{ccc}
\hline Slab & $\begin{array}{c}\text { Total Energy } \\
(\mathrm{eV})\end{array}$ & $\begin{array}{c}\text { Energy per Atom } \\
(\mathrm{eV})\end{array}$ \\
\hline 4 & -78.60 & -4.91 \\
\hline 5 & -99.31 & -4.97 \\
\hline 6 & -119.99 & -5.00 \\
\hline 7 & -140.78 & -5.03 \\
\hline 8 & -161.44 & -5.04 \\
\hline 9 & -182.26 & -5.06 \\
\hline 10 & -202.95 & -5.07 \\
\hline 12 & -244.47 & -5.09 \\
\hline
\end{tabular}

Total energy (E) was computed based on formula, $\mathrm{E}=\sum_{i}^{n} \varepsilon_{i}+\frac{1}{2} \iint \frac{\rho(r) \rho\left(r^{\prime}\right)}{\left|r-r^{\prime}\right|} d r d r^{\prime}+\mathrm{E}_{X C}[\rho]-\int V_{X C}(r) \rho(r) d r$, where $\mathrm{n}=$ electrons, $\varepsilon_{i}=$ the energy of the Kohn-Sham orbital, $\mathrm{r}=$ electron coordinate, $\rho(r)=$ ground-state electron density, $\mathrm{E}_{X C}=$ exchange correlation energy, and $V_{X C}=$ exchange correlation potential [28].

The more the model, the more negative the total energy, which means the model is more stable. However, the simpler model, the better. Therefore, based on Figure 2, we choose $7^{\text {th }}$ slab model for the model of $2 \times 2 \mathrm{Pd}$ (111) because at the $7^{\text {th }}$ slab the slope starts to be less sharp compared to 4 to 6 slab models. Defining Ni's role to the catalytic performance of PdNi alloy, we significantly alloyed the Ni to Pd by 1: 1 of ratio. However, we modeled the surface as monometallic $\mathrm{Pd}$ to adapt the synthesis's acid condition where the interaction of $\mathrm{Pd}$ and $\mathrm{H}$

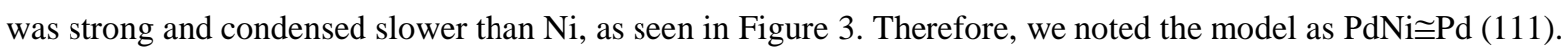
We also considered the surface (111) rather than (110) or (111) because $\operatorname{Pd}(111)$ surface shows the highest catalytic selectivity for $\mathrm{H}_{2} \mathrm{O}_{2}$ among the three surfaces [29].

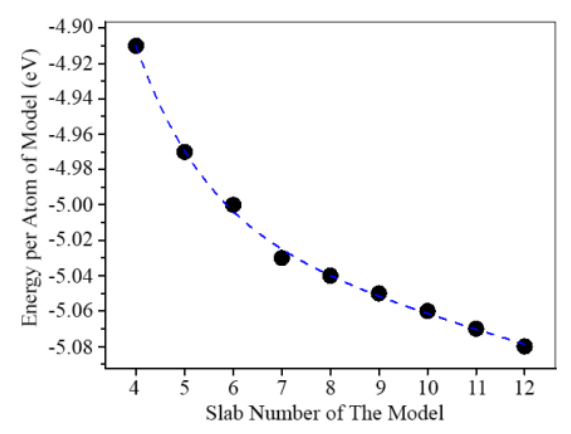

Figure 2. Energy per atom of the model.

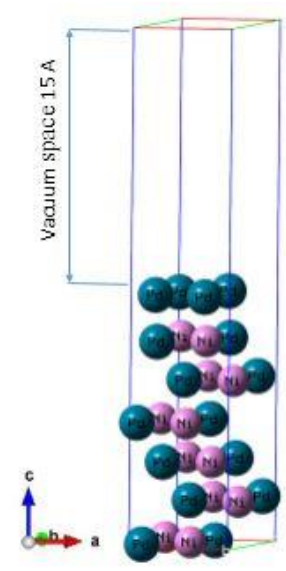

Figure 3. The 7 slabs alloy model of PdNi 2 x 2. Dark cyan and violet balls balls represent Pd and Ni atoms, respectively. 


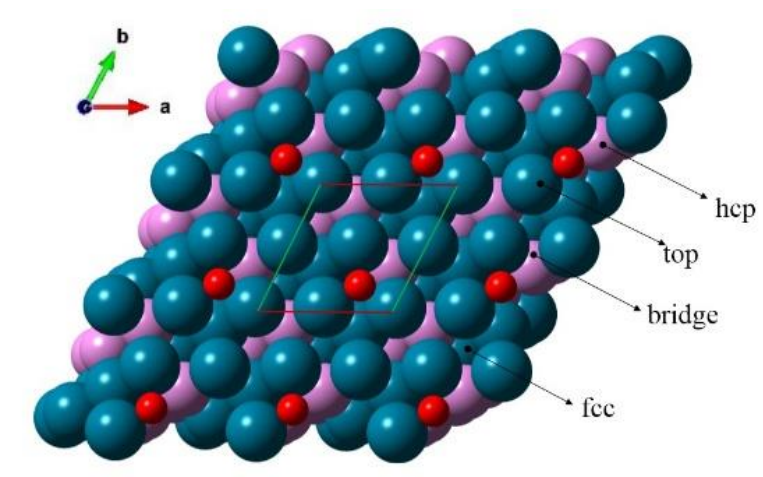

Figure 4. The $2 \times 2$ surface size of the $\mathrm{PdNi}(111)$ adsorption site in top view (c axis) widened toward a and $\mathrm{b}$ axes. Dark cyan, violet, and smaller red balls represent $\mathrm{Pd}, \mathrm{Ni}$, and $\mathrm{O}$ atoms, respectively.

Calculating the adsorption energy of species such as atomic oxygen, the species-surface distance was $2.6 \AA$ before optimization. The most substantial adsorption is located at FCC (face-centered cubic) site, followed successively by HCP (hexagonal closest pack) and bridge sites, and the weakest is on the top site, see Figure 4.

Adsorption energy of atomic oxygen was calculated as follow [18],

$$
E_{\mathrm{b} . \mathrm{O}}=E_{\mathrm{b} . \mathrm{O} / \text { surface }}-E_{\text {clean }}-1 / 2 E_{\mathrm{O} 2}
$$

where $E_{\mathrm{b} . \mathrm{O}}$ is oxygen adsorption energy, $E_{\mathrm{b} . \mathrm{O} / \text { surface }}$ is the total energy of adsorbed $\mathrm{O}$ on the surface, $E_{\text {clean }}$ is the total energy of bare $\mathrm{Pd}(111)$, and $E_{\mathrm{O} 2}$ is total energy of molecular oxygen as the gas state. Considering the stability of the catalyst as an important aspect, we calculated the binding energies, which is to define the energy needed for one atom on the surface to disassemble into single atom, using the formula adopted from previous research,[30] as follow,

$$
E_{\mathrm{b}}=\frac{E_{\text {surface }}+E_{\text {core }}+E_{\text {slab }}}{\mathrm{N}_{\text {surface }}}
$$

where $E_{\mathrm{b}}$ is binding energy, $E_{\text {surface }}$ is total energy of shell, $E_{\text {core }}$ is total energy of core, $E_{\text {slab }}$ is total energy of bare $\mathrm{Pd}(111)$, and $\mathrm{N}_{\text {surface }}$ is atom number of surface.

\section{Results and Discussion}

Based on Table 3, the presence of Ni in the PdNi@Pd(111) weakened $0.22 \mathrm{eV} \mathrm{O}$ adsorption energy compared to the monometallic $\mathrm{Pd}(111)$ surface. Based on our previous work,[9] the weakening of $\mathrm{O}$ adsorption energy on the $\mathrm{PdAu}(111)$ surface is also $0.20 \mathrm{eV}$ compared to the monometallic $\mathrm{Pd}(111)$ surface. Because O adsorption energy on PdNi@Pd(111) and PdAu(111) has the same trend, which is $0.2 \mathrm{eV}$ lower value compared to that on the monometallic $\operatorname{Pd}(111)$, the catalytic selectivity of $\operatorname{Pd}(111)$, $\mathrm{PdAu}(111), \mathrm{PdHg}(111)$ and $\mathrm{PdNi} @ \mathrm{Pd}(111)$ is discussed later based on $\mathrm{O}_{2}$ and $\mathrm{O}$ adsorption energy trends. The comparison of O adsorption energy on Pd(111) and PdNi@Pd(111) can be seen in Table 3, while O's adsorption configuration is in Figure 4.

\subsection{Trend of $\mathrm{O}_{2}$ and $\mathrm{O}$ Adsorption on The Pd-Based Catalyst Surface}

Considering the $\mathrm{H}_{2} \mathrm{O}_{2}$ synthesis, we explored the interaction of $\mathrm{O}_{2}$ to the surface since the adsorption energy of $\mathrm{O}_{2}$ determined the presence of $\mathrm{O}_{2}{ }^{*}$, which lead to the final product $\mathrm{H}_{2} \mathrm{O}_{2}$. We did not consider the presence of $\mathrm{H}_{2}$ in this working since $\mathrm{H}_{2}$ adsorbed dissociated to $\mathrm{H}^{*}$ on the $\mathrm{Pd}(111)$. Based on the direct synthesis mechanism of $\mathrm{H}_{2} \mathrm{O}_{2}$, the presence of $\mathrm{O}_{2} *$ is the key. The adsorption energy of $\mathrm{O}_{2}$ should be 'enough' to facilitate the $\mathrm{O}_{2} *$ hydrogenation for $\mathrm{HOOH}$ formation. If the interaction of $\mathrm{O}_{2}$ and surface is too strong, the adsorbed $\mathrm{O}_{2}$ can be dissociated to $2 \mathrm{O}^{*}$. However, if the $\mathrm{O}_{2}$ surface interaction is too weak, $\mathrm{O}_{2}$ may be released to the gas state. There is no exact number of interaction strength for the reference for finding a good catalyst. 
Table 3. The comparison of $\mathrm{O}$ adsorption energy on 2 x 2 slabs of $\mathrm{Pd}(111)$ and $\mathrm{PdNi}(111)$ models.

\begin{tabular}{lc}
\hline Catalyst & Adsorption Energy of O (eV) \\
\hline $\mathrm{Pd}(111)$ & -1.23 \\
\hline $\mathrm{PdNi} @ \mathrm{Pd}(111)$ & -1.01 \\
\hline
\end{tabular}

Table 4. Adsorption energy of $\mathrm{O}_{2}$ and $\mathrm{O}$ on the various surfaces.

\begin{tabular}{lcc}
\hline Catalyst & Adsorption Energy of $\mathrm{O}_{2}(\mathrm{eV})$ & Adsorption Energy of O $(\mathrm{eV})$ \\
\hline $\mathrm{Pd}(111)$ & -1.07 & -1.65 \\
\hline $\mathrm{PdAu}(111)$ & -0.88 & -1.46 \\
\hline $\mathrm{PdHg}(111)$ & -0.87 & -1.40 \\
\hline
\end{tabular}

Identifying the interaction between $\mathrm{O}_{2}$ and candidate catalysts, we compared the adsorption energy among the well-known catalysts. For example, $\mathrm{PdAu}(111)$ alloy is the better catalyst proven in experimental compared to monometallic Pd. Based on Table 4, the adsorption energy of $\mathrm{O}_{2}$ on the better catalyst $\mathrm{PdAu}(111)$ alloy is lower compared to $\mathrm{Pd}(111)$. The Adsorption energy of $\mathrm{O}_{2}$ on $\mathrm{PdHg}(111)$ alloy is closed to that on $\mathrm{PdAu}(111)$ alloy, which leads to the conclusion that $\mathrm{PdHg}(111)$ alloy also the better catalyst compared to $\mathrm{Pd}(111)$. The lower adsorption energy can be a better catalyst that was explored in previous research.

Edwards et al. [10] showed that the $\operatorname{PdAu}(111)$ alloy has better catalytic performance than monometallic $\mathrm{Pd}$, see Table 5 . The acid condition improves catalyst selectivity and productivity significantly. The role of acid is to suppress the $\mathrm{O}_{2} *$ dissociation caused by the change of surface characteristic, which weakens the interaction of $\mathrm{O}_{2}-\mathrm{Pd}$. A forementioned in Table 4, the strong interaction of $\mathrm{O}_{2}-\mathrm{Pd}$ may lead to the dissociation of $\mathrm{O}_{2} *$ to $2 \mathrm{O}^{*}$. The presence of $\mathrm{Au}$ or $\mathrm{Hg}$ in the alloy of $\mathrm{PdAu}(111)$ or $\mathrm{PdHg}(111)$ decreases $0.2 \mathrm{eV}$ of $\mathrm{O}_{2}$ the adsorption energy on alloy surfaces compared to the monometallic Pd surface.

The spontaneous reaction of $\mathrm{H}_{2} \mathrm{O}_{2}$ formation andthe kinetic and thermodynamic information was usually named as Bronsted-Evan Polanyi (BEP) relation. BEP relation has used to prove the higher composition of $\mathrm{Au}$ or $\mathrm{Hg}$ alloyed to $\mathrm{Pd}$, the higher barrier energy to dissociate $\mathrm{O}_{2} *$ to $2 \mathrm{O}^{*}$, the more $\mathrm{O}_{2}{ }^{*}$ presence [9]. Even, the energy barrier for $\mathrm{O}_{2}{ }^{*}$ formation was higher than $\mathrm{OOH}$ formation, which meant that the main key of $\mathrm{H}_{2} \mathrm{O}_{2}$ formation was related to the adsorbed $\mathrm{O}_{2}$ on the surface.

The existence of $\mathrm{O}_{2}{ }^{*}$ was the main focus in this work since it can lead to the comparison of catalytic performance among the catalysts. As seen in Table 4, the adsorption energy of $\mathrm{O}_{2}$ on the surfaces of the catalyst has the same trend as adsorption of atomic $\mathrm{O}$ [4]. Therefore, calculating the adsorption energy of $\mathrm{O}$ can be used to predict the trend of $\mathrm{O}_{2}$ adsorption energy on the same catalyst surfaces. Since the atomic $\mathrm{O}$ adsorption can predict the trend of $\mathrm{O}_{2}$ adsorption among different surfaces, while the $\mathrm{O}_{2}$ adsorption can predict the relative selectivity, we considered the $\mathrm{O}$ adsorption as a "selector" to find the new catalyst.

The calculation of O's adsorption energy is easier and faster compared to the calculation of $\mathrm{O}_{2}$ adsorption. Therefore, we chose the adsorbed atomic oxygen to be used to predict the relative catalytic selectivity of the candidate catalyst, such as $\mathrm{PdNi} \cong \mathrm{Pd}(111)$. Based on the same trend of $\mathrm{O}_{2}$ and $\mathrm{O}$ adsorption energy on surfaces of $\mathrm{PdAu}(111), \mathrm{PdHg}(111)$, and $\mathrm{PdNi} \cong \mathrm{Pd}(111)$ compared to monometallic catalyst $\mathrm{Pd}(111), \mathrm{PdNi} \cong \mathrm{Pd}(111)$ shows the possibility of a new catalyst for $\mathrm{H}_{2} \mathrm{O}_{2}$ direct synthesis.

Table 5. Comparison of catalyst composition and selectivity.

\begin{tabular}{lcc}
\hline Catalyst & Treatment & Selectivity (\%) \\
\hline $5 \% \mathrm{Pd} / \mathrm{C}$ & - & 42 \\
\hline $5 \% \mathrm{Pd} / \mathrm{C}$ & $2 \% \mathrm{HNO} 3$ & 42 \\
\hline $2.5 \% \mathrm{Au}-2.5 \% \mathrm{Pd} / \mathrm{C}$ & - & 80 \\
\hline $2.5 \% \mathrm{Au}-2.5 \% \mathrm{Pd} / \mathrm{C}$ & $2 \% \mathrm{CH}_{3} \mathrm{COOH}$ & 98 \\
\hline
\end{tabular}


Table 6. Comparison of binding energy $\left(E_{b}\right)$ on $\operatorname{Pd}(111)$ and $\operatorname{PdNi}(111)$.

\begin{tabular}{lc}
\hline Catalyst & $E_{b . \mathrm{Pd}}, \mathrm{eV} /$ atom \\
\hline $\mathrm{Pd}(111)$ & 1.23 \\
\hline $\mathrm{PdNi} @ \mathrm{Pd}(111)$ & 1.12 \\
\hline
\end{tabular}

The catalytic performance of $\mathrm{PdAu}(111)$ or $\mathrm{PdHg}(111)$ compared to the monometallic $\mathrm{Pd}(111)$ catalyst was explored using "in silico" approach. The catalytic kinetic was studied by calculating reaction steps to get energy barrier information to indicate the reaction rate. The catalytic thermodynamic was observed by calculating the reaction energy to identify.

\section{2. $P d N i \cong P d(111)$ Stability}

The stability of the catalyst is also an important factor in getting the optimum catalytic process. Therefore we investigated the stability of PdNi@Pd(111) by calculating the binding energy defined as the energy needed to release one atom from its bulk structure, as seen in Table 6 . The binding energies of monometallic $\mathrm{Pd}(111)$ and $\mathrm{PdNi} \cong \mathrm{Pd}(111)$ were $1.23 \mathrm{eV}$ and $1.12 \mathrm{eV}$, respectively, which means that one atom requires $1.23 \mathrm{eV}$ and $1.12 \mathrm{eV}$, respectively, to be removed from their structure.

Based on binding, the bimetallic $\operatorname{PdNi} \cong \operatorname{Pd}(111)$ alloy has less stable than the monometallic $\operatorname{Pd}(111)$. However, the difference of binding energy between monometallic and bimetallic $\mathrm{PdNi} \cong \mathrm{Pd}(111)$ alloys is relatively small so that by referring to the stability of monometallic $\mathrm{Pd}$, the structure of $\mathrm{PdNi} \cong \mathrm{Pd}(111)$ has adequate stability as a catalyst for direct synthesis of $\mathrm{H}_{2} \mathrm{O}_{2}$.

\section{Conclusion}

The bimetallic gold-palladium alloy or $\mathrm{PdAu}(111)$ is the well-known catalyst for $\mathrm{H}_{2} \mathrm{O}_{2}$ synthesis. However, the gold has limited availability in the nature and we propose $\mathrm{Ni}$ as the alternative alloyed to Pd(111). To investigate PdNi@Pd (111) alloy as the catalyst, we compare PdNi@Pd(111) alloy with catalysts that have been proven based on the literatures, such as $\mathrm{Pd}(111), \operatorname{PdAu}(111)$, and $\mathrm{PdHg}(111)$ by using atomic $\mathrm{O}$ adsorption energy as the basis of observation. Based on our calculations, the metal $\mathrm{Ni}$ alloyed to metal $\mathrm{Pd}$ causes the atomic oxygen adsorption energy on the surface of the $\mathrm{PdNi} \cong \mathrm{Pd}$ (111) to be the same trend as the surface of $\mathrm{PdAu}(111)$ and $\mathrm{PdHg}(111)$ compared to monometallic catalyst $\mathrm{Pd}$, which indicates the equivalent catalyst selectivity among catalysts of $\mathrm{PdNi} \cong \mathrm{Pd}$ (111), $\mathrm{PdAu}(111)$, and $\mathrm{PdHg}(111)$ alloys. Considering this fact, we also calculate the $\mathrm{PdNi} \cong \mathrm{Pd}$ (111) alloy's stability compared with the monometallic $\mathrm{Pd}$ to prove that $\mathrm{PdNi} \cong \mathrm{Pd}$ (111) alloy stability is acceptable. Thus, this paper proposes $\mathrm{PdNi} \cong \mathrm{Pd}$ (111) alloy as a cheaper catalyst choice compared to $\mathrm{PdAu}(111)$. However, this work has some limitations that need further exploration, such as Pd surface electronic change caused by Ni presence. The ratio of $\mathrm{Ni}$ and $\mathrm{Pd}$ in the core catalyst structure model can be further investigated to determine the composition's effect on the catalytic selectivity. The surface alloy between Pd and Ni also needs to be studied to determine surface composition's effect on the catalytic selectivity.

\section{References}

[1] S. H. Zeronian and M. K. Inglesby, "Bleaching of cellulose by hydrogen peroxide," Cellulose, vol. 2, no. 4, pp. 265-272, 1995.

[2] J. M. Campos-Martin, G. Blanco-Brieva, and J. L. Fierro, "Hydrogen peroxide synthesis: an outlook beyond the anthraquinone process," Angew. Chem. Int. Ed. Engl., vol. 45, no. 42, pp. 6962-6984, 2006.

[3] S. Abate, G. Centi, S. Perathoner, S. Melada, F. Pinna, and G. Strukul, "The issue of selectivity in the direct synthesis of $\mathrm{H}_{2} \mathrm{O}_{2}$ from $\mathrm{H}_{2}$ and $\mathrm{O}_{2}$ : the role of the catalyst in relation to the kinetics of reaction," Top. Catal., vol. 38, no. 1-3, pp. 181-193, 2006.

[4] M. Nugraha, M. C. Tsai, J. Rick, W. N. Su, H. L. Chou, and B. J. Hwang, "DFT study reveals geometric and electronic synergisms of palladium-mercury alloy catalyst used for hydrogen peroxide formation," Appl. Catal. A., no. 547, pp. 69-74, 2017. 
[5] H. W. Kim, M. B. Ross, N. Kornienko, L. Zhang, J. Guo, P. Yang, and B. D. McCloskey, "Efficient hydrogen peroxide generation using reduced graphene oxide-based oxygen reduction electrocatalysts," Nature Catalysis, vol. 1, no. 4, p. 282-290, 2018.

[6] E. Santacesaria, M. D. Serio, R. Velotti, and U. Leone, "Kinetics, mass transfer, and palladium catalyst deactivation in the hydrogenation step of the hydrogen peroxide synthesis via anthraquinone," Ind. Eng. Chem. Res., vol. 33, no. 2, pp. 277-284, 1994.

[7] J. Li and K. Yoshizawa, "Mechanistic aspects in the direct synthesis of hydrogen peroxide on PdAu catalyst from first principles," Cat. Today, vol. 248, pp. 142-148, 2015.

[8] C. A. Farberow, A. Godinez-Garcia, G. Peng, J. F. Perez-Robles, O. Solorza-Feria, and M. Mavrikakis, "Mechanistic studies of oxygen reduction by hydrogen on PdAg(110)," ACS Catal., vol. 3, no. 7, pp. 1622-1632, 2013.

[9] M. Nugraha, M. C. Tsai, W. N. Su, H. L. Chou, and B. J. Hwang, "Descriptor study by density functional theory analysis for the direct synthesis of hydrogen peroxide using palladium-gold and palladium-mercury alloy catalysts," Molecular Systems Design \& Engineering, vol. 3, no. 6, pp. 896-907, 2018.

[10] J. K. Edwards, B. Solsona, E. Ntainjua, A. F. Carley, A. A. Herzing, C. J. Kiely, and G. J. Hutchings, "Switching off hydrogen peroxide hydrogenation in the direct synthesis process," Science, vol. 323, no. 5917, pp. 1037-1041, 2009.

[11] B. D. Adams, C. K. Ostrom, and A. Chen, "Highly active PdPt catalysts for the electrochemical reduction of $\mathrm{H}_{2} \mathrm{O}_{2}$," Journal of The Electrochemical Society, vol. 158, no. 4, pp. B434-B439, 2011.

[12] S. Siahrostami et al., "Enabling direct $\mathrm{H}_{2} \mathrm{O}_{2}$ production through rational electrocatalyst design," Nat. Mater., vol. 12, no. 12, pp. 1137-1143, 2013.

[13] A. Verdaguer-Casadevall et al., "Trends in the electrochemical synthesis of $\mathrm{H}_{2} \mathrm{O}_{2}$ : enhancing activity and selectivity by electrocatalytic site engineering," Nano Lett., vol. 14, no. 3, pp. 16031608, 2014.

[14] H. C. Kazici, F. Salman, and H. D. Kivrak, "Synthesis of Pd-Ni/C bimetallic materials and their application in non-enzymatic hydrogen peroxide detection," Materials Science-Poland, vol. 35, no. 3, pp. 660-666, 2017.

[15] X. Lv, C. Bai, S. He, and Q. Huang, "Mineral change of Philippine and Indonesia nickel lateritic ore during sintering and mineralogy of their sinter," ISIJ Int., vol.50, no. 3, pp. 380-385, 2010.

[16] R. Sari, S. Hammoudeh, and U. Soytas, "Dynamics of oil price, precious metal prices, and exchange rate," Energy Economics, vol. 32, no. 2, pp. 351-362, 2010.

[17] R. Dittmeyer, J. D. Grunwaldt, and A. Pashkova, "A review of catalyst performance and novel reaction engineering concepts in direct synthesis of hydrogen peroxide," Cat. Today, vol. 248, pp. 149-159, 2015.

[18] P. C. Jennings, H. A. Aleksandrov, K. M. Neyman, and R. L. Johnston, " $\mathrm{O}_{2}$ dissociation on $\mathrm{M} \cong \mathrm{Pt}$ core-shell particles for 3d, 4d, and 5d transition metals," J. Phys. Chem. C., vol. 119, no. 20, pp. 11031-11041, 2015.

[19] A. M. Joshi, W. N. Delgass, and K. T. Thomson, "Investigation of gold-silver, gold-copper, and gold-palladium dimers and trimers for hydrogen peroxide formation from $\mathrm{H}_{2}$ and $\mathrm{O}_{2}$," J. Phys. Chem. C., vol. 111, no. 20, pp. 7384-7395, 2007.

[20] H. C. Ham, G. S. Hwang, J. Han, S. W. Nam, and T. H. Lim, "On the role of Pd ensembles in selective $\mathrm{H}_{2} \mathrm{O}_{2}$ formation on PdAu alloys," J. Phys. Chem. C., vol. 113, no. 30, pp. 12943-12945, 2009.

[21] J. Zhang, B. Huang, Q. Shao, and X. Huang, "Highly active, selective and stable direct $\mathrm{H}_{2} \mathrm{O}_{2}$ generation by monodispersive Pd-Ag nanoalloy," ACS applied materials \& interfaces, vol. 10, no. 25, pp. 21291-21296, 2018.

[22] J. K. Edwards et al., "Switching off hydrogen peroxide hydrogenation in the direct synthesis process," Science, vol. 323, no. 5917, pp. 1037-1041, 2009.

[23] F. Gao and D. W. Goodman, "Pd-Au bimetallic catalysts: understanding alloy effects from planar models and (supported) nanoparticles," Chem. Soc. Rev., vol. 41, no. 24, pp. 8009-8020, 2012.

[24] H. Guesmi, "Theoretical insights on the effect of reactive gas on the chemical ordering of goldbased alloys," Gold Bul., vol. 46, no.4, pp. 213-219, 2013. 
[25] Y. Nomura, T. Ishihara, Y. Hata, K. Kitawaki, K. Kaneko, and H. Matsumoto, "Nanocolloidal $\mathrm{Pd}-\mathrm{Au}$ as catalyst for the direct synthesis of hydrogen peroxide from $\mathrm{H}_{2}$ and $\mathrm{O}_{2}$," Chem. Sus. Chem., vol. 1, no. 7, pp. 619-621, 2008.

[26] P. Landon et al., "Direct synthesis of hydrogen peroxide from $\mathrm{H}_{2}$ and $\mathrm{O}_{2}$ using $\mathrm{Pd}$ and $\mathrm{Au}$ catalysts," Phys. Chem. Chem. Phys., vol. 5, no. 9, pp. 1917-1923, 2003.

[27] J. Li, A. Staykov, T. Ishihara, and K. Yoshizawa, "Theoretical study of the decomposition and hydrogenation of $\mathrm{H}_{2} \mathrm{O}_{2}$ on $\mathrm{Pd}$ and $\mathrm{Au} \cong \mathrm{Pd}$ surfaces: understanding toward high selectivity of $\mathrm{H}_{2} \mathrm{O}_{2}$ synthesis," J. Phys. Chem. C., vol. 115, no.15, pp. 7392-7398, 2011.

[28] H. Eschrig, The Fundamentals of Density Functional Theory. Dresden: Springer, 2003.

[29] P. Tian, L. Ouyang, X. Xu, J. Xu, and Y. F. Han, "Density functional theory study of direct synthesis of $\mathrm{H}_{2} \mathrm{O}_{2}$ from $\mathrm{H}_{2}$ and $\mathrm{O}_{2}$ on $\mathrm{Pd}(111), \mathrm{Pd}(100)$, and $\mathrm{Pd}(110)$ surfaces," Chin. J. Catal., vol. 34, pp. 1002-1012, 2013.

[30] G. E. R. Caballero and P. B. Balbuena,"Surface segregation of core atoms in core-shell structures," Chem. Phys. Lett., vol. 456, pp. 64-67, 2008. 